\title{
Introducing Second Language Acquisition: Perspectives and Practices
}

\author{
Kirsten M. Hummel
}

Chichester, England: Wiley Blackwell, 2014, 273 pages, ISBN: 9780470658048

Hummel's recent book offers a straightforward introduction to second language acquisition (SLA) for readers who are new to this area. It comprises 10 chapters: an introductory and concluding chapter, and eight chapters that cover key topics in SLA. The chapters are organized in a clear and concise manner, and each includes self-assessment questions, discussion questions, and ideas for projects/exercises. A series of fictional language learners are introduced in the first chapter, and these learners are then used to provide illustrative examples of concepts discussed in the book. A number of textboxes labelled "Language learning in practice" are also included throughout the book. These offer "practical applications of discussed research and practice" (p. 4). For example, in a section describing the Audiolingual Method of teaching, one of these textboxes offers an example of an audiolingual classroom drill.

The choice of chapter topics offers a nice overview of SLA. Chapter 2 begins with an introduction to first language acquisition, covering a basic description of first language development and an overview of theoretical views of first language development. The chapter concludes by connecting first language acquisition to second language acquisition. Chapter 3 introduces language learning contexts, including both naturalistic contexts (e.g., immigration) and instructed learning contexts (e.g., traditional classroom instruction and dual language instruction). In Chapters 4 and 5 Hummel provides a nice balance between theory and practice, with Chapter 4 introducing some of the more prominent theories of SLA while Chapter 5 gives a historical overview of teaching approaches. Although it is impossible to cover either of these topics comprehensively in single chapters, Hummel does an admirable job of hitting the key aspects of each area that newcomers to SLA should be familiar with. She also discusses the somewhat difficult relationship between SLA theories and teaching approaches, which is important for understanding SLA research and practice.

Chapter 6 covers second language development, and again Hummel is able to take a topic that has a broad scope and simplify it while still hitting on most of the key points. This chapter includes descriptions of second language processes and influences such as cross-linguistic influence and developmental sequences; it then goes on to discuss linguistic subareas such as phonology and learner language. Chapters 7 and 8 cover learner background characteristics, with Chapter 7 devoted entirely to the role of age in SLA, and individual differences such as aptitude, motivation, and personality are discussed in Chapter 8. Age is a heavily researched and much debated issue in 
language learning and development; however, this is the one chapter in the book that may cover a topic in more detail than is needed for an introductory textbook, particularly given the breadth of other topics that are covered in single chapters.

Finally, Chapter 9 gives an overview of bilingualism, including types of bilingualism, debates around the impact of bilingualism on linguistic and cognitive development, and bilingual language development. Chapter 10, the final chapter of the textbook, gives a brief wrap-up as well as an epilogue to the life stories of the learner profiles that were introduced in the first chapter.

Overall, this book offers an accessible and reader-friendly introduction to SLA. It would be particularly useful for introductory courses at the undergraduate level. Hummel manages to cover a wide range of topics related to SLA without the text become overly dense or intimidating. The book is well designed, with cartoons and textboxes breaking up the main text and clear introductions and summaries provided to drawn a reader's attention to the most crucial information. The book is well referenced and does a good job of discussing specific research studies that inform the topics being discussed. A particular strength of this book is the suggestions for further reading and viewing. Along with providing references for books and articles that readers may find useful, references and URLs for a large number of free online videos are also included. Many of these include talks and demonstrations from experts in the field and would be of interest to students who want to explore content areas further. Overall, this book is highly recommended for instructors who are looking for a solid and reader-friendly introductory SLA textbook for their students, or for any reader seeking a comprehensive yet approachable introductory text in this area.

Jennifer Foote

\section{The Reviewer}

Jennifer Foote is an Assistant Professor in the Faculty of Extension at the University of Alberta. Her research interests include second language speech perception, pronunciation instruction, and computer-assisted language learning.

\section{An Introduction to English Sentence Structure: Clauses, Markers, Missing Elements}

Jon Jonz

Sheffield, UK: Equinox Publishing, 2014, 285 pages, ISBN 978-184553-146-1

This grammar book will certainly be appreciated by those who are curious to dip their toes in the waters of functional grammar. In this introduction to English sentence structure, the focus is mainly on how event structure, the things that happen in our everyday lives, is represented in language. 